\title{
Stability of selected chlorinated thiazide diuretics
}

\author{
K. Deventer ${ }^{\mathrm{a}, *}$, G. Baele ${ }^{\mathrm{b}}$, P. Van Eenoo ${ }^{\mathrm{a}}$, O.J. Pozo ${ }^{\mathrm{a}}$, F.T. Delbeke ${ }^{\mathrm{a}}$ \\ a DoCoLab, UGent, Department of Clinical Chemistry, Microbiology and Immunology, Technologiepark 30, B-9052 Zwijnaarde, Belgium \\ ${ }^{\mathrm{b}}$ Department of Applied Mathematics and Computer Science, Krijgslaan 281, S9, B-9000 Gent, Belgium
}

\section{A R T I C L E I N F O}

\section{Article history:}

Received 6 August 2008

Received in revised form 5 November 2008

Accepted 6 November 2008

Available online xxx

\section{Keywords:}

Doping

Urine

Diuretics

Thiazides

Sports

Stability-study

\begin{abstract}
A B S T R A C T
In sports, diuretics are used for two main reasons: to flush previously taken prohibited substances with forced diuresis and in sports where weight classes are involved to achieve acute weight loss. A common property observed for thiazides is hydrolysis in aqueous media resulting in the formation of the degradation product aminobenzenedisulphonamide. This degradation product can be observed for several thiazides. Because there is limited information regarding the effect of $\mathrm{pH}$, temperature and light on the stability of thiazides, these parameters were investigated for chlorothiaizide, hydrochlorothiazide and altizide. For all three compounds the degradation product could be detected after incubation at $\mathrm{pH}$ 9.5 for $48 \mathrm{~h}$ at $60^{\circ} \mathrm{C}$. At lower $\mathrm{pH}$ and temperature the degradation product could not be detected for all compounds. When samples were exposed to UV-light altizide and hydrochlorothiazide were photodegraded to chlorothiazide. When the degradation rate between the different compounds was compared for a given temperature and $\mathrm{pH}$, altizide is the most unstable compound. This study confirms that thiazide degradation products can be formed in urine during transport. Hence doping control laboratories shall include them into their routine testing methods as required by WADA.
\end{abstract}

(c) 2008 Elsevier B.V. All rights reserved.

\section{Introduction}

Diuretics are an indispensable group of therapeutics used to regulate the excretion of water and salts by increasing the urinary flow. In sports they are used to flush previously taken prohibited substances with forced diuresis or, in sports where weight classes are involved, to achieve acute weight loss. Diuretics are banned in sports by the World Anti-Doping Agency (WADA) [1] and cover a wide range of chemical products. A therapeutical important group of diuretics are the thiazides (Table 1 ). Thiazides cover a whole class of structurally related compounds and have a common structure consisting out of two fused heterocyclic rings (Table 1). Only a few thiazides are mentioned in the prohibited list of WADA [1], i.e. bendroflumethiazide (BFMT), chlorothiazide (CLT) and hydrochlorothiazide (HCT). However, since the prohibited list is not limitative, doping control laboratories screen for a large number of thiazides [2-5].

A common property observed for thiazides is hydrolysis in aqueous media. This hydrolysis has been described firstly by Yamana et al. [6] and in the framework of doping control analysis by Thieme et al. [2]. Because of possible degradation in urine, Goebel et al. [3] highlighted the importance to include the degradation prod-

\footnotetext{
* Corresponding author. Tel.: +32 9 3313295; fax: +32 93313299 E-mail address: koen.Deventer@UGent.be (K. Deventer).

URL: http://www.docolab.UGent.be (K. Deventer).
}

ucts into screening methods for diuretics. During hydrolysis the substituent $R_{3}$ is lost and a degradation product with a common skeleton is obtained (Table 1 ). This degradation product is known as aminobenzenedisulphonamide $(\mathrm{AB})$. Depending on the functional groups $R_{2}, R_{4}$ and $R_{6}$, in the parent thiazide different degradation products can be formed. Because altizide (ALT), CLT and HCT only differ in substituent $\mathrm{R}_{3}$ a common degradation product, aminochlorobenzenedisulphonamide (ACB), is obtained. Yamana et al. [6,7] found that both $\mathrm{pH}$ and temperature affected the degradation of CLT and HCT. In another study the reversibility and reaction mechanism of HCT were further investigated [8]. All these studies were conducted at elevated temperatures $\left(60^{\circ} \mathrm{C}\right.$ and $\left.90^{\circ} \mathrm{C}\right)$ in aqueous buffers while no urinary matrices were investigated. An approach at elevated temperature $\left(100^{\circ} \mathrm{C}\right)$ in a urinary matrix was described for BFMT [9]. The authors focused on the long term photodegradation ( $>20$ days exposure to light) of bendroflumethiazide at $\mathrm{pH} 5$ and 7 . They concluded that light has only a minor effect on the degradation contrary to the important effect of $\mathrm{pH}$. Another study performed at our laboratory investigated the stability in urinary matrices of several doping agents including thiazides [10]. The degradation of the thiazides was studied on a qualitative basis without determination of degradation rates.

The aim of this study was to determine the relationship between degradation rate and $\mathrm{pH}$ or temperature, both in urinary and aqueous matrices. In contrast to the previous work this study was performed at lower temperatures, e.g.: $20^{\circ} \mathrm{C}, 40^{\circ} \mathrm{C}$ and $60^{\circ} \mathrm{C}$. ALT, CLT and HCT were investigated because both ALT and HCT are 
Table 1

Chemical structures and degradation products of several thiazide drugs.

\begin{tabular}{|c|c|c|c|c|}
\hline & & & de & $\underset{\text { Aminobenzenedisulphonamide }(\mathrm{AB})}{\text { ous }}$ \\
\hline & $\mathrm{R}_{2}$ & $\mathrm{R}_{3}$ & $\mathrm{R}_{4}$ & $\mathrm{R}_{6}$ \\
\hline Altizide (ALT) & $\mathrm{H}$ & & $\mathrm{H}$ & $\mathrm{Cl}$ \\
\hline Chlorothiazide (CLT) & $\mathrm{H}$ & $\mathrm{H}$ & 3,4 ene & $\mathrm{Cl}$ \\
\hline Hydrochlorothiazide (HCT) & $\mathrm{H}$ & $\mathrm{H}$ & $\mathrm{H}$ & $\mathrm{Cl}$ \\
\hline $\begin{array}{l}\text { Bendroflumethiazide (BFMT) } \\
\text { Hydroflumethiazide (HFMT) }\end{array}$ & $\begin{array}{l}\mathrm{H} \\
\mathrm{H}\end{array}$ & $\mathrm{H}$ & $\begin{array}{l}\mathrm{H} \\
\mathrm{H}\end{array}$ & $\begin{array}{l}\mathrm{CF}_{3} \\
\mathrm{CF}_{3}\end{array}$ \\
\hline
\end{tabular}

commercially available drugs on the Belgian market. CLT was also included because it can be detected as a metabolite of HCT and ALT (unpublished results). The results of this study could allow doping control authorities and doping control laboratories to consider critical parameters which can induce or increase degradation during transportation and sample preparation.

\section{Experimental}

\subsection{Chemicals and reagents}

HCT and CLT were obtained from Ciba-Geigy (Groot-Bijgaarden, Belgium), mefruside from Bayer Belgium (Brussels, Belgium) and ALT from Continental Pharma (Brussels). Acetazolamide was purchased from Cyanamid Benelux (Brussels) and ACB was from Sigma-Aldrich (Bornem, Belgium). Methanol p.a. (MeOH), formic acid p.a. (HCOOH), HPLC grade acetonitrile (ACN) and HPLC grade water were from Acros (Geel, Belgium). Buffer pH 2.0 consisting of $6.34 \mathrm{~g}$ citric acid trihydrate and $3.58 \mathrm{~g}$ sodium chloride in $1 \mathrm{~L}$ aqua bidest, $\mathrm{pH}$ adjustment was performed with hydrochloric acid (3 M). Buffer pH 5.2: $68 \mathrm{~g}$ sodium acetate dissolved in $1 \mathrm{~L}$ aqua bidest, $\mathrm{pH}$ was adjusted using acetic acid. Buffer $\mathrm{pH}$ 7: $35.5 \mathrm{~g}$ disodiumhydrogenphosphate dihydrate and $7.0 \mathrm{~g}$ sodiumdihydrogene phopshate dissolved in $500 \mathrm{~mL}$ aqua bidest, $\mathrm{pH}$ adjusted with phosphoric acid and the buffer $\mathrm{pH} 9.2$ was prepared by dissolving $200 \mathrm{~g}$ ammonium chloride in $500 \mathrm{~mL}$ aqua bidest, $\mathrm{pH}$ was adjusted with ammonium hydroxide (25\%). All reagents for preparing the buffers were p.a. grade from Merck (Darmstadt, Germany).

\subsection{Instrumentation}

Temperature experiments were performed in a Heraeus laboratory oven (Liedekerke, Belgium) with a continuous temperature control. For the experiments under standard laboratory light conditions OSRAM fluorscent lamps $(58 \mathrm{~W})$ were used while the experiments under UV-light (Spectronics CM-26) were done at $356 \mathrm{~nm}$ (intensity: $350 \mu \mathrm{W} / \mathrm{cm}^{2}$ ). Qualitative analyses were performed on an ion trap instrument using previously described experimental settings [5]. Semi-quantitative experiments were done on a Quantum Discovery mass spectrometer (Thermo, San Jose, CA, USA) equipped with an ESI source, operated in the positive ionisation mode.

The ESI voltage was set to $3000 \mathrm{~V}$. Capillary temperature was $300^{\circ} \mathrm{C}$ and the sheath gas flow rate was arbitrary set at 70 units. No auxilliary gas was used. The mass spectrometer was operated in the SRM mode and the isolation width was set 0.7 FWHM. The scan speed and scan width were maintained at $10 \mathrm{~ms}$ and $0.01 \mathrm{amu}$, respectively. The collision gas pressure was 1.5 mTorr for all the compounds.

\subsection{Experimental set-up}

The stability study was divided into two parts: the first part was developed to determine the formation of ACB and was based upon a qualitative set-up [10]. In the second part the degradation speed was determined using a semi-quantitative approach [11].

In the qualitative part the three compounds were spiked in the four buffers at a concentration of $10 \mu \mathrm{g} / \mathrm{mL}$. The solutions were then kept at $20^{\circ} \mathrm{C}, 40^{\circ} \mathrm{C}$ and $60^{\circ} \mathrm{C}$ for $48 \mathrm{~h}$. Additionally, the experiments at $20^{\circ} \mathrm{C}$ were performed under laboratory light, daylight and UV light $(365 \mathrm{~nm})$. Afterwards the samples were cooled to $2^{\circ} \mathrm{C}$ using a Memmert cooling bath (Schwabach, Germany) and $50 \mu \mathrm{L}$ mefruside solution $(20 \mu \mathrm{g} / \mathrm{mL})$ were added as internal standard. In the semi-quantitative approach the three compounds were spiked in triplicate at concentrations of $10 \mu \mathrm{g} / \mathrm{mL}$ in both urinary and aqueous matrices. For the experiments in water $1 \mathrm{~mL}$ of bidest water and $1 \mathrm{~mL}$ of the buffer were mixed and for the experiments in urinary matrix $1 \mathrm{~mL}$ of urine and $1 \mathrm{~mL}$ of the buffer. The samples were evaluated at pH 5.2 and 7 (normal physiological range of urine) at $20^{\circ} \mathrm{C}, 40^{\circ} \mathrm{C}$ and $60^{\circ} \mathrm{C}$ during $5 \mathrm{~h}(300 \mathrm{~min})$. Aliquots were collected after $30 \mathrm{~min}, 60 \mathrm{~min}, 90 \mathrm{~min}, 120 \mathrm{~min}, 150 \mathrm{~min}, 180 \mathrm{~min}, 210 \mathrm{~min}$, $240 \mathrm{~min}, 270 \mathrm{~min}$ and $300 \mathrm{~min}$ exposure and cooled to $2^{\circ} \mathrm{C}$ using a Memmert cooling bath and $50 \mu \mathrm{L}$ acetazolamide $(20 \mu \mathrm{g} / \mathrm{mL})$ was added as internal standard.

\subsection{Evaluation of the results}

For the qualitative approach the evaluation of the results afterwards was based upon three repetitions of every experiment. The criterion for the detection was the presence of an ion trace in the respective selected ion chromatogram with a signal-to-noise $(\mathrm{S} / \mathrm{N})>3$ at the expected retention time.

For the quantitative approach the average degradation speed related to $\mathrm{pH}$ and temperature was calculated using a multiple linear regression model. The logarithmic area ratios $(\ln (A R s))$ served as dependent variables, and time and temperature and their interactions were added as independent variables in the analysis. A one-way analysis of variance (ANOVA) was used to detect differences in degradation speed over time.

Post hoc analyses were performed to determine which of the degradation speeds differed between temperatures.

Regardless of the outcome of the ANOVA, it was tested if each individual degradation speed differed from zero. Accounting for multiple testing using the Dunn-Sidak correction, three (two) 
Table 2

Qualitative degradation experiments, shielded from light, during $48 \mathrm{~h}$ at different $\mathrm{pH}$ and temperatures.

\begin{tabular}{|c|c|c|c|c|c|c|c|}
\hline \multirow[t]{2}{*}{ Compound } & \multirow[t]{2}{*}{$\mathrm{pH}$} & $20^{\circ} \mathrm{C}$ & $40^{\circ} \mathrm{C}$ & $60^{\circ} \mathrm{C}$ & $20^{\circ} \mathrm{C}$ & $40^{\circ} \mathrm{C}$ & $60^{\circ} \mathrm{C}$ \\
\hline & & \multicolumn{3}{|c|}{ Detection parent } & \multicolumn{3}{|c|}{ Detection ACB } \\
\hline \multirow{4}{*}{ ALT } & 2.0 & $3 / 3^{a}$ & $3 / 3$ & $3 / 3$ & ND & $3 / 3$ & $3 / 3$ \\
\hline & 5.2 & $3 / 3$ & ND & ND & $3 / 3$ & $3 / 3$ & $3 / 3$ \\
\hline & 7.0 & ND & ND & ND & $3 / 3$ & $3 / 3$ & $3 / 3$ \\
\hline & 9.2 & ND & ND & ND & $3 / 3$ & $3 / 3$ & $3 / 3$ \\
\hline \multirow{4}{*}{$\mathrm{HCT}$} & 2.0 & $3 / 3$ & $3 / 3$ & $3 / 3$ & ND & ND & $3 / 3$ \\
\hline & 5.2 & $3 / 3$ & $3 / 3$ & $3 / 3$ & ND & $3 / 3$ & $3 / 3$ \\
\hline & 7.0 & $3 / 3$ & $3 / 3$ & $3 / 3$ & $3 / 3$ & $3 / 3$ & $3 / 3$ \\
\hline & 9.2 & $3 / 3$ & $3 / 3$ & ND & $3 / 3$ & $3 / 3$ & $3 / 3$ \\
\hline \multirow{4}{*}{ CLT } & 2.0 & $3 / 3$ & $3 / 3$ & $3 / 3$ & ND & ND & ND \\
\hline & 5.2 & $3 / 3$ & $3 / 3$ & $3 / 3$ & ND & ND & ND \\
\hline & 7.0 & $3 / 3$ & $3 / 3$ & $3 / 3$ & ND & ND & ND \\
\hline & 9.2 & $3 / 3$ & $3 / 3$ & ND & $3 / 3$ & $3 / 3$ & $3 / 3$ \\
\hline
\end{tabular}

ND: not detected.

a Number of positive detection/total number of repetitions of the experiment.

98.30\% (97.47\%) confidence intervals were calculated, one for the degradation speed at each temperature. Alongside of the confidence intervals, the corresponding $p$-values are reported as well.

\section{Results and discussion}

\subsection{Qualitative experiments}

The results of the qualitative experiments, performed shielded from light, are presented in Table 2. At pH 2.0 all parent compounds

Table 3

Qualitative degradation experiments, shielded from light, during $2 \mathrm{~h}$ at $60^{\circ} \mathrm{C}$.

\begin{tabular}{clll}
\hline Compound & $\mathrm{pH}$ & $60^{\circ} \mathrm{C}$ & \\
\cline { 3 - 4 } & & Detection parent & Detection ACB \\
\hline \multirow{3}{*}{ ALT } & 2.0 & $3 / 3^{\mathrm{a}}$ & $\mathrm{ND}$ \\
& 5.2 & $3 / 3$ & $3 / 3$ \\
& 7.0 & $3 / 3$ & $3 / 3$ \\
& 9.2 & $\mathrm{ND}$ & $3 / 3$ \\
$\mathrm{HCT}$ & 2.0 & $3 / 3$ & $\mathrm{ND}$ \\
& 5.2 & $3 / 3$ & $\mathrm{ND}$ \\
& 7.0 & $3 / 3$ & $3 / 3$ \\
& 9.2 & $3 / 3$ & $3 / 3$ \\
CLT & 2.0 & $3 / 3$ & $\mathrm{ND}$ \\
& 5.2 & $3 / 3$ & $\mathrm{ND}$ \\
& 7.0 & $3 / 3$ & $\mathrm{ND}$ \\
& 9.2 & $3 / 3$ & $3 / 3$ \\
\hline
\end{tabular}

ND: not detected.

a Number of positive detection/total number of repetitions of the experiment. were still present in the samples after $48 \mathrm{~h}$ incubation at $20^{\circ} \mathrm{C}, 40^{\circ} \mathrm{C}$ and $60^{\circ} \mathrm{C}$. For both ALT and HCT, ACB was detected indicating degradation. ACB was observed for ALT at all temperatures whereas for HCT only at $40^{\circ} \mathrm{C}$ and $60^{\circ} \mathrm{C}$. For CLT, ACB was not detected at any temperature.

After incubation at $\mathrm{pH} 5.2$, ALT could no longer be detected at $40^{\circ} \mathrm{C}$ and $60^{\circ} \mathrm{C}$ but $\mathrm{ACB}$ was present in all samples. For HCT, ACB was present at $40^{\circ} \mathrm{C}$ and $60^{\circ} \mathrm{C}$ and CLT was stable at all the temperatures.

At pH 7.0 ALT was completely degraded at all temperatures. On the other hand, HCT and CLT were still present in all samples and no ACB could be detected for CLT in any of the samples. At $\mathrm{pH}$ 9.2 degradation seemed to be faster as for both HCT and CLT, ACB was detected at all temperatures. At this $\mathrm{pH}$ none of the parent substances could be detected at $60^{\circ} \mathrm{C}$. These experiments clearly show that the combination of high temperature and $\mathrm{pH}$ results in a faster degradation which was also observed in the BFMT-study [9].

Because storage at $60^{\circ} \mathrm{C}$ had a pronounced effect on the degradation in the first experiments (Table 2), degradation during a short time period $(2 \mathrm{~h})$ at this temperature was investigated as well. The results are presented in Table 3. Even after this short time interval the degradation product could already be detected at elevated temperature and $\mathrm{pH}$. ALT could no longer be detected at $\mathrm{pH} 9.2$. Both CLT and HCT were detectable in all situations.

When the experiments performed at $20^{\circ} \mathrm{C}$ were conducted under artificial laboratory light or daylight the same results were obtained. Further, in the samples containing ALT and HCT, a peak for CLT was detected at $\mathrm{pH} 2$ (Fig. 1). At higher $\mathrm{pH}$ values this peak was

Table 4

Statistical analysis of the regression slopes comparing different temperatures.

\begin{tabular}{|c|c|c|c|c|c|c|c|}
\hline & $\mathrm{pH}$ & $R^{2}$ & ANO & & & & $p$-Value \\
\hline & 7 & 0.9870 & & -44 & & & \\
\hline ALT & & & $\begin{array}{l}1-2 \\
1-3 \\
2-3\end{array}$ & $\begin{array}{l}5.13 \times 10^{-12} \\
4.60 \times 10^{-44} \\
2.16 \times 10^{-33}\end{array}$ & $\begin{array}{l}1 \\
2 \\
3\end{array}$ & $\begin{array}{l}{\left[-1.5 \times 10^{-3} ;-4.2 \times 10^{-4}\right]} \\
{\left[-4.2 \times 10^{-3} ;-3.1 \times 10^{-3}\right]} \\
{\left[-1.1 \times 10^{-2} ;-9.6 \times 10^{-3}\right]}\end{array}$ & $\begin{array}{l}1.43 \times 10^{-4} \\
1.53 \times 10^{-26} \\
5.10 \times 10^{-59}\end{array}$ \\
\hline HCT & 7 & 0.9121 & & & $\begin{array}{l}1 \\
2 \\
3\end{array}$ & $\begin{array}{l}{\left[-1.3 \times 10^{-4} ; 8.7 \times 10^{-5}\right]} \\
{\left[-2.3 \times 10^{-4} ;-6.8 \times 10^{-6}\right]} \\
{\left[-3.2 \times 10^{-4} ;-9.6 \times 10^{-5}\right]}\end{array}$ & $\begin{array}{l}0.606 \\
1.14 \times 10^{-2} \\
2.11 \times 10^{-2}\end{array}$ \\
\hline CLT & 7 & 0.9779 & & & $\begin{array}{l}1 \\
2 \\
3\end{array}$ & $\begin{array}{l}{\left[-2.8 \times 10^{-4} ; 1.5 \times 10^{-4}\right]} \\
{\left[-1.2 \times 10^{-4} ; 3.0 \times 10^{-4}\right]} \\
{\left[-1.3 \times 10^{-4} ; 2.9 \times 10^{-4}\right]}\end{array}$ & $\begin{array}{l}0.855 \\
0.655 \\
0.745\end{array}$ \\
\hline
\end{tabular}

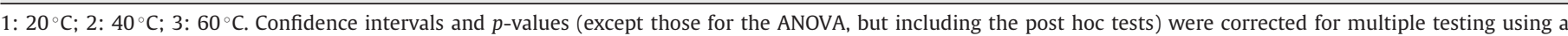
Dunn-Sidak correction. 

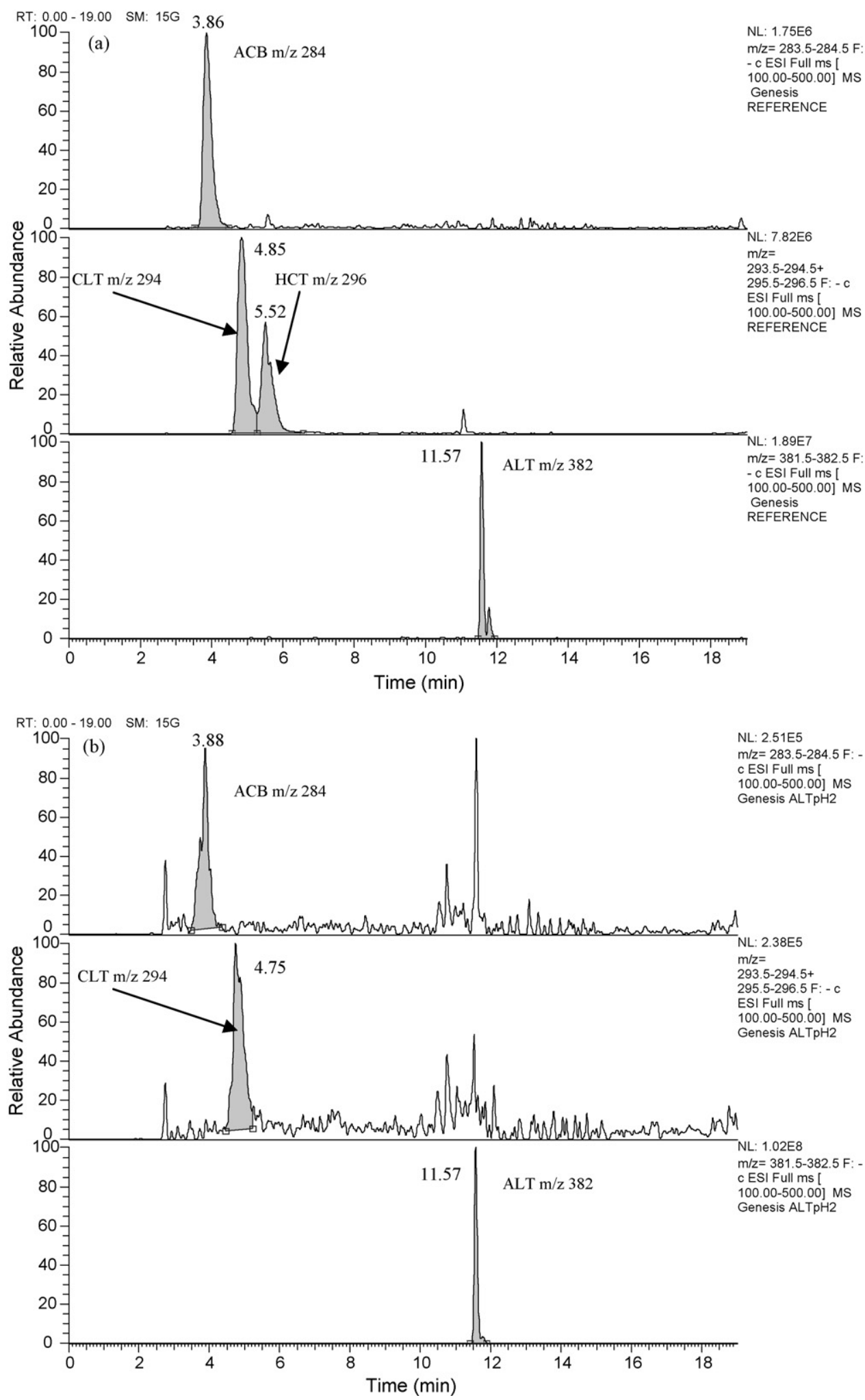

Fig. 1. Extracted ion chromatograms for ACB, CLT, HCT and ALT in a reference sample (a) and a sample containing ALT exposed to daylight for $48 \mathrm{~h}$ (b).

not detected. Additionally, another set of samples was exposed to UVA light ( $365 \mathrm{~nm}$ ) during $48 \mathrm{~h}$. The outcome was similar as for the experiments performed under daylight and CLT was only detected at $\mathrm{pH} 2.0$ for HCT and ALT. To the best of our knowledge such a transformation from ALT into CLT has not been previously reported. For HCT and BFMT photodegradation has been reported when samples were exposed to UVA light [9,12].

\subsection{Semi-quantitative experiments}

Stability studies are an important topic in the field of anti-doping analysis to ascertain the detection of all substances and to guarantee reproducible inter- and intra-laboratory results. Unfortunately few criteria for stability testing protocols are available. In 2004, Jimenez et al. [11] described a practical approach for this purpose. 


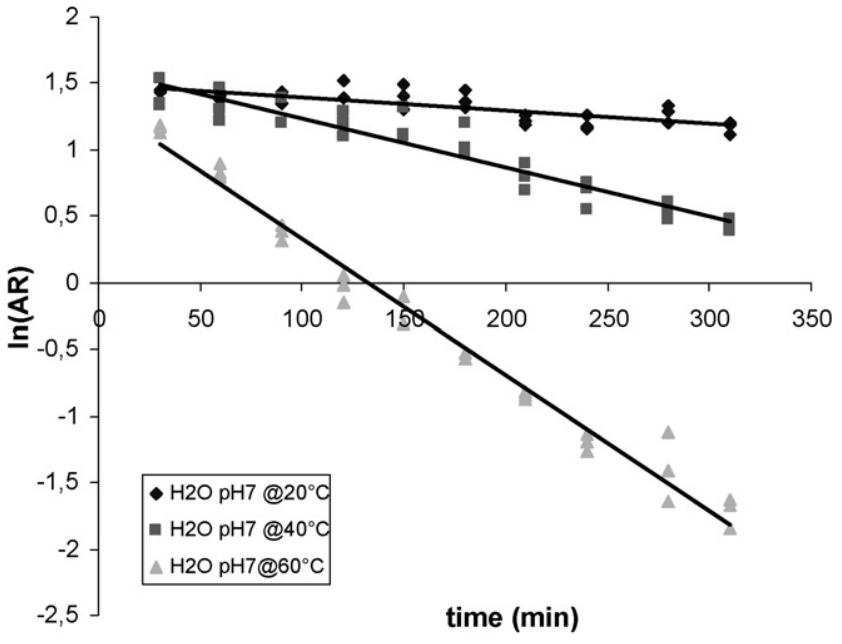

Fig. 2. Degradation rate of altizide in water at $\mathrm{pH} 7$.

The authors stated that stability studies, measuring concentrations in time, can be hampered by poor reproduciblity of the analytical method, in particular when ad hoc quantitative methods are developed for the stability studies. Jimenez et al. showed that acceptable results can be achieved, using a qualitative method and comparing the response (signal), given as the ARs of the analyte to the internal standard, with a reference stored under conditions where no degradation is observed. Since no quantitative method was available for the investigated thiazides the latter approach was applied. The references (without degradation) were the aliquots at $t_{0}$. By taking samples from this aliquot at several time points degradation rates were measured by determining if the slopes deviated from zero (Table 4).

Taking into account a previous study on the degradation of BFMT and the suggested first order mechanism [9] linear curves were fitted through the logarithmic ARs. $E\left[\ln (\mathrm{ARs})_{t}\right]=\ln (\mathrm{ARs})_{t_{0}}+k t$, where $E\left[\ln (\mathrm{ARs})_{t}\right]$ denotes the average $\ln (\mathrm{ARs})_{t}$ at time $t$ among subjects with baseline level $\ln (\mathrm{ARs})_{t_{0}}$, with $k=$ degradation speed; $t_{0}=$ start of the degradation; $t=$ degradation at a certain time point.

This final model was found to yield sufficiently high multiple correlation coefficients of an average $98 \%$, with the exception of one case where the correlation coefficient was about $91 \%$. There was no correction for multiple testing across experiments when performing the model comparison using ANOVA, as this would only affect

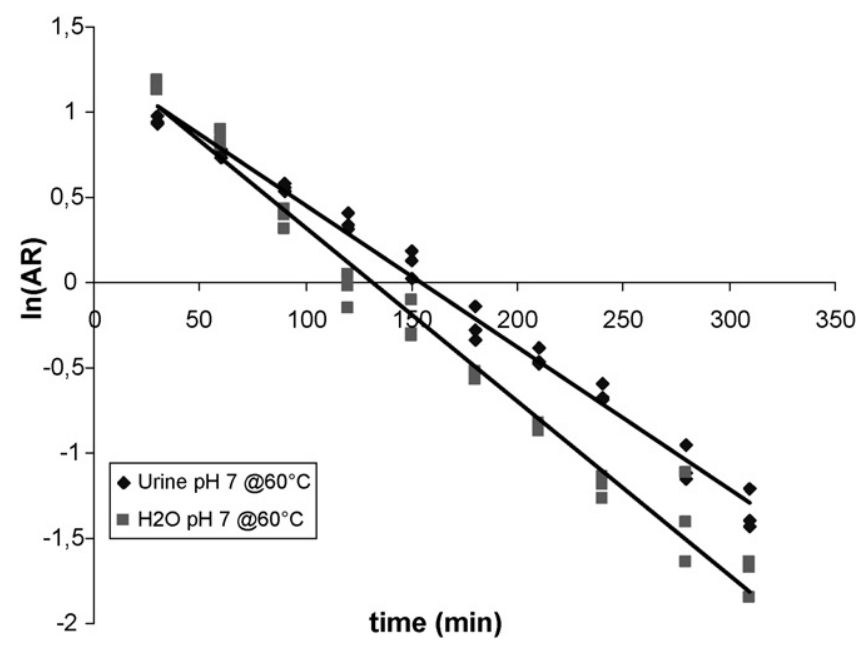

Fig. 3. Comparison of the degradation rate in urine and water for altizide at $60{ }^{\circ} \mathrm{C}$.

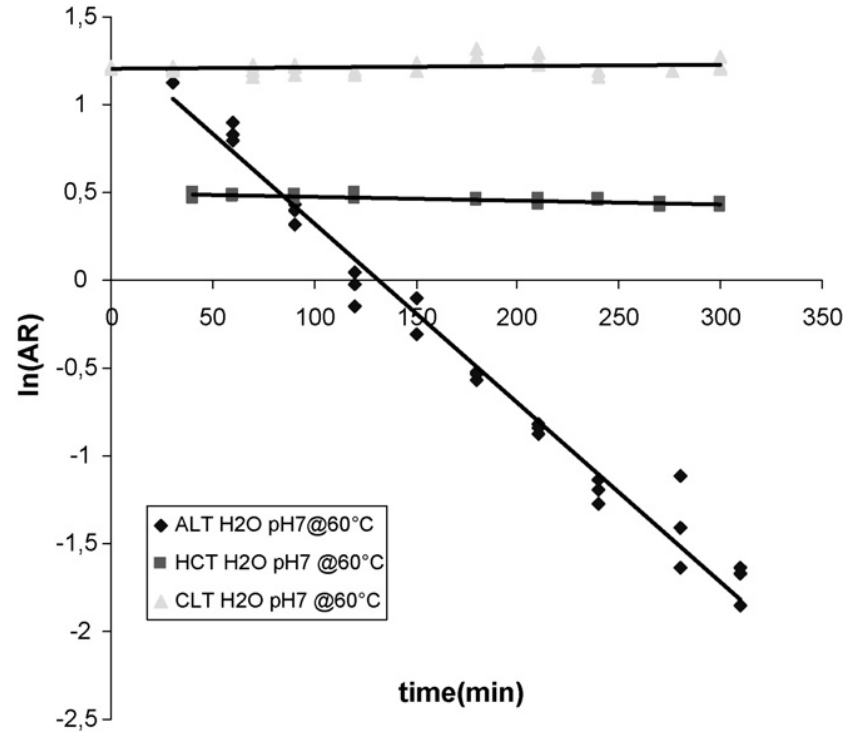

Fig. 4. Comparison of degradation rate for ALT, CLT and HCT at pH 7.

the outcome of one case, where the multiple correlation coefficient reported was the lowest ( $91 \%$ ).

Comparing the slopes for ALT at $20^{\circ} \mathrm{C}, 40^{\circ} \mathrm{C}$ and $60^{\circ} \mathrm{C}$ in water at $\mathrm{pH} 7$ a clear difference in degradation speed was found (Fig. 2). The fastest degradation was observed at $60^{\circ} \mathrm{C}$ and could be expected compared to the qualitative experiments (vide supra). At $60^{\circ} \mathrm{C}$ and $\mathrm{pH} 7$ half of the initial amount of ALT is lost after $82 \mathrm{~min}$ in the water samples. The linear trend analysis for the different slopes showed that they all three were significantly different from zero (Table 4). For HCT similar first order degradation kinetics as for ALT were observed and significant degradation was found at $40^{\circ} \mathrm{C}$ and $60^{\circ} \mathrm{C}$ (Table 4). At $20^{\circ} \mathrm{C}$ no degradation was detected. For CLT none of the slopes differed significantly from zero (Table 4) and therefore no degradation was found under the described experimental conditions.

Comparing degradation speed between $\mathrm{pH} 5.2$ and 7.0 for a given temperature yielded only for ALT a significant difference at $60^{\circ} \mathrm{C}$. For HCT and CLT no difference was detected at any temperature.

When urinary and aqueous matrices were compared the slopes of the curves in water were significantly steeper than those obtained in urine (Fig. 3). This faster degradation in water has also been found in the photodegradation study of BFMT [9].

As described in the qualitative experiments the formation of $A C B$ was also observed. Unfortunately, no linear correlation for this formation after plotting time versus ARs, $\ln$ (ARs) or 1/ARs was found. Two possibilities were suggested for this non-linear behaviour: the instability of $A C B$, or the linear range of the mass spectrometer was exceeded. Both hypotheses were investigated and none could explain this observation.

Finally, the plot of the degradation curves for the three substances at $\mathrm{pH} 7$ and $60^{\circ} \mathrm{C}$ (Fig. 4) clearly showed that ALT had the highest degradation rate, CLT is the most stable and the degradation speed for HCT lies in between.

\section{Conclusion}

This study has indicated that thiazide diuretics are subject to degradation to a different extent depending on $\mathrm{pH}$, light and temperature. At $\mathrm{pH} 2$ thiazide drugs were fairly stable even at elevated temperatures. The thiazide drugs degrade faster at higher $\mathrm{pH}$ values. 
Therefore it is recommended to cool or freeze urine samples during transport and storage.

As observed during the qualitative experiments chlorothiazide can be formed from altizide and hydrochlorothiazide after exposure to UVA light. This photodegradation is of lesser importance in the anti-doping field where samples are only exposed to laboratory light for a short time. The substances investigated in this study exhibited different degradation rates and altizide seemed to be the most unstable one. As previously observed for bendroflumethiazide degradation in urine was slower than in aqueous media. The statistical model applied in this work can also be useful to evaluate the stability for other compounds without the need for quantitation. Research investigating the detection of the degradation product aminochlorobenzenedisulphonamide in administration urines is ongoing.

\section{Acknowledgements}

The authors wish to thank WADA for financial support.

Postdoctoral grants by the Flemish Ministry of Culture, Youth, Sports and Brussels (PVE and KD) and the Spanish Ministerio de Educacion y Ciencia (OJP) are gratefully acknowledged.
The technical assistance of Joris De Backer was appreciated. We would also like to thank Stijn Vansteelandt for helpful discussion regarding the regression analysis.

\section{References}

[1] WADA, The World Anti-Doping Code, The 2008 Prohibited List, 2008 http://www.wada-ama.org/rtecontent/document/2008_List_En.pdf. (accesed November 4th, 2008).

[2] D. Thieme, J. Grosse, R. Lang, R.K. Mueller, A. Wahl, J. Chromatogr. B 757 (2001) 49-57.

[3] C. Goebel, G.J. Trout, R. Kazlauskas, Anal. Chim. Acta 502 (2004) 65-74.

[4] Y. Qin, X.B. Wang, C. Wang, M. Zhao, M.T. Wu, Y.X. Xu, et al., J. Chromatogr. B 794 (2003) 193-203.

[5] K. Deventer, P. Van Eenoo, F.T. Delbeke, Rapid Commun. Mass Spectrom. 19 (2005) 90-98.

[6] T. Yamana, Y. Mizukami, A. Tsuji, F. Ichimura, Z.-J. Yakugaku, Pharm. Soc. Jpn. 89 (1969) 740-744.

[7] T. Yamana, Y. Mizukami, A. Tsuji, Z.-J. Yakugaku, Pharm. Soc. Jpn. 89 (1969) $422-425$.

[8] J.A. Mollica, C.R. Rehm, J.B. Smith, H.K. Govan, J. Pharm. Sci. 60(1971) 1380-1384.

[9] M.J.R. Angel, M.T.G. Agusti,J.S.E. Romero, S.C. Broch, LC-GC Eur. 18(2005)32-40.

[10] P. Van Eenoo, L. Lootens, A. Spaerkeer, W. Van Thuyne, K. Deventer, F.T. Delbeke, J. Anal. Toxicol. 31 (2007) 543-548.

[11] C. Jimenez, R. Ventura, J. Segura, R. de la Torre, Anal. Chim. Acta 515 (2004) 323-331.

[12] L.K. Revelle, S.M. Musser, B.J. Rowe, I.C. Feldman, J. Pharm. Sci. 86 (1997) 631-634. 